\title{
Drug-Induced Pancreatitis (Lisinopril)
}

\author{
Lucinda G. Miller, PharmD, BCPS, and Grace Tan, MD
}

Medications are often overlooked as a potential cause of acute pancreatitis. In many cases we rely on postmarketing surveillance of new medications to characterize their adverse effect profile, which might include acute pancreatitis. Whereas estrogen-induced pancreatitis is relatively well-recognized, the association of pancreatitis with the newer agents such as angiotensin-converting enzyme (ACE) inhibitors (eg, lisinopril) and hydroxymethylglutaryl-coenzyme A (HMG-CoA) reductase inhibitors (eg, simvastatin) is less commonly recognized. We describe a case in which the temporal relation suggests lisinopril as the causative or exacerbating agent. As with alcohol-induced pancreatitis, drug-induced pancreatitis should improve with abstinence. Knowing which drugs are associated with inflammation of the pancreas will help family physicians to consider drug-induced causes in the setting of acute pancreatitis.

\section{Case Report}

A 42-year-old woman came to the emergency department with a chief complaint of abdominal pain in the mid-diaphragm epigastric area that had begun the previous evening. At that time she received trimethoprim-sulfamethoxazole for a presumed urinary tract infection. The next day, however, the pain, which continued, became more severe and precipitated a second visit to the emergency department. The patient, who weighed 174 pounds, reported no diarrhea, gas, or fever, but she did vomit white, intermittently green, vomitus with no blood.

Her medical history included hypertension and

Submitted, revised, 20 May 1998.

From the Department of Primary Care (LGM), and the Department of Pharmacy Practice (LGM), School of Pharmacy, Texas Tech University Health Sciences Center, Amarillo; and the Department of Family Medicine (GT), School of Medicine, Texas Tech University Health Sciences Center, Amarillo. Address reprint requests to Lucinda G. Miller, PharmD, BCPS, Department of Pharmacy Practice, School of Pharmacy, Texas Tech University Health Sciences Center, 1300 Coulter, Amarillo, TX 79106-1712. angina, presumed to be secondary to coronary artery disease. Her surgical history included a hysterectomy (which included an appendectomy in 1988), breast lumpectomy (in 1989), cholecystec- ® tomy secondary to cholecystitis (in 1993), and bi- $\vec{\circ}$ lateral salpingo-oophorectomy (in 1997). She had $\stackrel{\omega}{N}$ a family history of hypertriglyceridemia affecting $\stackrel{N}{N}$ both her father and sister. Her current medications prescribed by her primary care physician are listed in Table 1 ; she admitted, however, to intermittent compliance with the drug regimens. Additionally, the patient was taking sublingual nitroglycerin $0.4 \mathrm{mg}$ as-needed. She denied alcohol use but did smoke cigarettes, one-half pack per day for 30 years.

When she was examined, her temperature was $97.5^{\circ} \mathrm{F}$, her respirations were increased at 20 breaths per minute, her heart rate was rapid at 98 beats per minute, and her blood pressure was 120/90 mmHg. Her abdomen had diminished bowel sounds with diffuse tenderness, and she had increased tenderness in the epigastric and right upper quadrant areas. There was no rebound tenderness, rigidity, or guarding. Her laboratory values were as follows: sodium $123 \mathrm{mEq} / \mathrm{L}$, chloride 96 $\mathrm{mEq} / \mathrm{L}$, bicarbonate $21 \mathrm{mEq} / \mathrm{L}$, potassium 3.4 $\mathrm{mg} / \mathrm{dL}$, creatinine $0.5 \mathrm{mg} / \mathrm{dL}$, blood urea nitrogen (BUN) $10 \mathrm{mg} / \mathrm{dL}$, blood glucose $104 \mathrm{mg} / \mathrm{dL}$, triglycerides $11,271 \mathrm{mg} / \mathrm{dL}$, cholesterol 692 $\mathrm{mg} / \mathrm{dL}$, amylase $117 \mathrm{U} / \mathrm{L}$, and lipase $200 \mathrm{U} / \mathrm{L}$. Her urinalysis was positive for nitrites and negative for leukocyte esterase; there were moderate bacteria levels and occult blood. Her white blood cell count was $16,500 / \mathrm{mL}$, hemoglobin $15.1 \mathrm{~g} / \mathrm{dL}$, hematocrit 39.2 percent, and platelets $347,000 / \mu \mathrm{L}$.

Her condition was diagnosed as acute pancreatitis and possible urinary tract infection for which she received one dose of trimethoprim-sulfamethoxazole. She was admitted to the family medicine service for hydration and gastrointestinal tract rest. An abdominal computed tomographic (CT) scan showed normal pancreatic and biliary duct systems with no stones or anatomic obstruc- 
Table 1. Patient's Medication History.

\begin{tabular}{|c|c|c|c|}
\hline Drug & $\begin{array}{l}\text { Dose } \\
\text { (mg) }\end{array}$ & $\begin{array}{c}\text { Daily } \\
\text { Regimen }\end{array}$ & $\begin{array}{l}\text { Duration of } \\
\text { Therapy }\end{array}$ \\
\hline $\begin{array}{l}\text { Nicardipine } \\
\text { (Norvase) }\end{array}$ & 5.0 & 1 & $3 y$ \\
\hline $\begin{array}{l}\text { Metoprolol } \\
\text { (Toprol XI) }\end{array}$ & 100.0 & 1 & $3 \mathrm{mo}$ \\
\hline $\begin{array}{l}\text { Estrogen } \\
\text { (Premarin) }\end{array}$ & 0.625 & 1 & $1 y$ \\
\hline $\begin{array}{l}\text { Isosorbide mononitrate } \\
\text { (Imdur) }\end{array}$ & 60.0 & 1 & $3 \mathrm{mo}$ \\
\hline $\begin{array}{l}\text { Lisinopril } \\
\text { (Zestril) }\end{array}$ & 40.0 & 1 & $3 \mathrm{mo}$ \\
\hline $\begin{array}{l}\text { Omeprazole } \\
\text { (Prilosec) }\end{array}$ & 20.0 & 4 & $7 \mathrm{mo}$ \\
\hline $\begin{array}{l}\text { Simvastatin } \\
\text { (Zocor) }\end{array}$ & 20.0 & 1 at bedtime & $3 \mathrm{mo}$ \\
\hline $\begin{array}{l}\text { Nitroglycerin, } \\
\text { sublingual }\end{array}$ & 0.4 & as needed & \\
\hline
\end{tabular}

tions, but there was diffuse homogenous enlargement of head and body of the pancreas compatible with extensive pancreatitis. This finding was consistent with her elevated amylase and lipase levels. Her triglyceride levels were elevated but her cholesterol level was elevated as well, presumably secondary to noncompliance with the simvastatin regimen.

When able to tolerate oral intake, she resumed her regimen of nicardipine, metoprolol, isosorbide mononitrate, and omeprazole for hypertension, coronary artery disease, and nonspecific gastrointestinal symptoms, respectively. Her oral estrogen was changed to transdermal estrogen, a form preferred in patients with pancreatitis. Lisinopril and simvastatin were discontinued because they can potentially cause pancreatitis, and her hypertriglyceridemia was treated with gemfibrozil. She was discharged after the 5 th day (after symptoms had resolved and pancreatic enzyme levels returned to normal) and scheduled for follow-up with her primary care physician.

She was readmitted 2 months later with epigastric pain diagnosed as gastroenteritis. She had continued to take conjugated estrogens (Premarin) and had begun taking simvastatin (Zocor) again despite being instructed not to do so. This rechallenge did not result in resurgence of her pancreatitis. Her amylase and lipase levels were within the normal limits. Pancreatitis was ruled out, and she was discharged in good health within 48 hours with a diagnosis of viral gastroenteritis. Although a psychiatric consultation was not obtained, somati- zation and a family history of hypertriglyceridemia could have predisposed the patient to frequent gastrointestinal complaints.

\section{Discussion}

Drug-induced pancreatitis, a relatively rare occurrence, affected only 1.4 percent $(n=22)$ of 1613 patients undergoing treatment for acute pancreatitis in 1993 in Germany. ${ }^{1}$ The molecular underpinnings for drug-induced pancreatitis remain to be elucidated and could be drug-specific. For example, it has been theorized that ACE inhibitors might cause pancreatitis by inducing localized angioedema. ${ }^{2}$ The relative risk of this adverse drug reaction is unknown because it is impossible to answer how frequently the application of a certain drug leads to acute pancreatitis. ${ }^{1}$ As Lankisch et al $^{1}$ aptly state, prospective studies pose logistic problems, and reexposure to suspected drugs is difficult to justify ethically.

Cortisone and thiazide diuretics were the first drugs associated with acute pancreatitis, ${ }^{3,4}$ and approximately 50 drugs have now been determined to be causative agents in pancreatitis. ${ }^{5,6}$ The most common drug associated with pancreatitis is alcohol. Other offending drugs include azathioprine, furosemide, hydrochlorothiazide, estrogens, and sulfasalazine. A complete list is provided in Table 2. Relatively new to this list are the ACE inhibitors (eg, lisinopril), HMG-CoA reductase inhibitors (eg, simvastatin), and dideoxynucleosides (eg, didanosine).

It has been only recently recognized that $\mathrm{ACE}$ inhibitors can cause pancreatitis. ${ }^{7}$ In the only other published case to date, an abrupt, severe, fulminant course of pancreatitis occurred in a 57-year-old man who had taken lisinopril $20 \mathrm{mg} / \mathrm{d}$ for hypertension for 10 months. ${ }^{8} \mathrm{He}$ denied alcohol use and had a mildly elevated triglyceride level of 178 $\mathrm{mg} / \mathrm{dL}$. His abdomen was distended and rigid with rebound tenderness, and the patient met 8 of Ranson's 11 prognostic signs. Surgical debridement of necrotic pancreatic tissue was necessary, but the patient died 2 days postoperatively. The occurrence of reported pancreatitis secondary to $\mathrm{ACE}$ inhibitors is relatively rare and has been confined to 30 cases associated with captopril, 20 cases associated with lisinopril, and 50 cases secondary to enalapril on file with their respective manufacturers. ${ }^{2}$ The seriousness of these cases, however, warrants extreme caution in predisposed patients. 
Table 2. Drugs Associated With Pancreatitis.

\begin{tabular}{ll}
\hline Acetaminophen & Isoniazid \\
Asparaginase & Lisinopril \\
Atorvastatin & Lovastatin \\
Calcium & Mercaptopurine \\
Captopril & Mesalazine \\
Chlorothiazide & Methyldopa \\
Chlorthalidone & Metronidazole \\
Cimetidine & Opioids \\
Cisplatin & Pentamidine \\
Clozapine & Phenformin \\
Colchicine & Procainamide \\
Corticosteroids & Propoxyphene \\
Cyclosporin & Quinapril \\
Cyproheptadine & Rifampicin \\
Diazoxide & Salicylates \\
Didanosine (ddI) & Simvastatin \\
Enalapril & Sulfasalazine \\
Estrogens & Sulindac \\
Ethacrynic acid & Tetracycline \\
Fosinopril & Valproic acid \\
Furosemide & Vinblastine \\
Gold & Vincristine \\
Hydrochlorothiazide & Zalcitabine (ddC) \\
Indomethacin & \\
\hline
\end{tabular}

The association of HMG-CoA reductase inhibitors with pancreatitis is even less well-known. A 46-year-old man with a family history of hypercholesterolemia developed epigastric pain after 1 week of treatment with lovastatin $40 \mathrm{mg} / \mathrm{d} .{ }^{9} \mathrm{He}$ also had Gilbert syndrome. Lovastatin was discontinued after his amylase level increased to 627 $\mathrm{U} / \mathrm{L}$ on day 26 . Rechallenge at a reduced dosage (lovastatin $10 \mathrm{mg}$ in the evening) 6 months later resulted in prompt recurrence of epigastric pain after only two to three doses, again leading to drug discontinuation.

Less conclusive is the case of a 59-year-old man taking lovastatin $20 \mathrm{mg} / \mathrm{d}$ who developed gastrointestinal bleeding. ${ }^{10} \mathrm{He}$ was given intravenous cimetidine (also known to cause pancreatitis). He underwent endoscopic retrograde cholangiopancreatography and sphincterotomy with biopsy to rule out a pancreaticobiliary malignancy, and his condition was diagnosed as aspirininduced ulcer of the major duodenal papilla. His postprocedural course was complicated by superficial thrombophlebitis of the leg and mild pancreatitis, both of which resolved spontaneously with supportive care.

In a third case, a 55-year-old man received lovastatin $20 \mathrm{mg}$ twice daily; 9 months later gemfibrozil $300 \mathrm{mg}$ twice daily was added. ${ }^{11}$ Within 2 months of combination therapy, he developed epigastric tenderness and vomiting and had a serum amylase of $3001 \mathrm{U} / \mathrm{L}$. Within 11 days of discontinuing both lovastatin and gemfibrozil, his serum amylase level returned to normal. Lovastatin was restarted 4 weeks later with no symptomatic recurrence for more than 2 years. Hence, it appears that lovastatin independently was not the offender, but when lovastatin was combined with fibric acid derivatives (ie, gemfibrozil), pancreatitis occurred.

Four cases of pancreatitis have been reported with simvastatin use. A 55-year-old woman had abdominal pain and vomiting that required hospital admission secondary to pancreatitis associated with 3 months' use of simvastatin $10 \mathrm{mg} / \mathrm{d} .{ }^{12}$ The patient improved rapidly after drug discontinuation. Acute pancreatitis with hepatic cytolysis developed in a 67-year-old woman receiving gemfibrozil and simvastatin $10 \mathrm{mg} / \mathrm{d} .{ }^{13}$ A third patient (50-year-old man) was hospitalized with severe epigastric pain, vomiting, and obstipation 12 hours after a single 20 -mg dose of simvastatin. ${ }^{14} \mathrm{~A}$ fourth patient with familial hypercholesterolemia developed persistent left flank pain when taking simvastatin $10 \mathrm{mg} / \mathrm{d}$. The pain resolved and laboratory findings returned to normal within 2 weeks of simvastatin discontinuation but recurred upon resumption of treatment. ${ }^{15}$ One pancreatic adverse event has been recorded in clinical trials involving $2502 \mathrm{pa}$ tients taking atorvastatin (V Leung, Parke-Davis Warner Lambert, Morris Plains, NJ, personal communication, November 1997). No cases of pancreatitis have been reported to date with pravastatin (MJ Toner, Bristol-Myers Squibb Company, Princeton, NJ, personal communication, November 1997).

These studies highlight the variable temporal relation between onset of drug therapy and development of pancreatitis. They also show that use of multiple medications associated with pancreatitis predispose the patient to such a reaction. Such reports are consistent with our patient, who was exposed to multiple medications that might have caused or exacerbated pancreatitis.

Most of these adverse effects have been reported in case reports in which selection bias results in reporting the most serious, often fatal, cases. Severe cases leading to death, however, are not representative of clinical practice. As indicated in the German study of 45 gastroenterology centers, only 1.4 percent of cases of drug-induced pancreatitis were considered to be drug induced. Most (86 percent) did not display any necroses on sonog- 
raphy or computed tomography, and only two outcomes (9 percent) were fatal. Drug-induced pancreatitis is thus overall considered to be of low severity. ${ }^{1}$ Our case is consistent with the latter in that our patient did not have an acute abdomen but rather had severe epigastric pain and elevated amylase and lipase levels that resolved with food restriction and removal of the offending agents.

Our patient's history suggests lisinopril was the causative agent. While it can be argued that sulfamethoxazole could have exacerbated our patient's condition, her symptoms predated the administration of trimethoprim-sulfamethoxazole, and she was given only one dose. Although it could also be argued that estrogen was the mediating factor in her pancreatitis, she had been taking the estrogen for 1 year without incident. Nevertheless, the estrogen could have predisposed this patient to pancreatitis, as would her high-risk status secondary to a family history of hypertriglyceridemia and her simvastatin use.

Hyperlipidemic pancreatitis is relatively rare, accounting for 1.3 to 3.5 percent of cases of pancreatitis. ${ }^{16}$ It occurs most commonly in poorly controlled diabetic patients who have a history of hypertriglyceridemia. ${ }^{17}$ Our patient, however, was not diabetic, and although her triglyceride level was elevated, her cholesterol levels were also elevated, which we presumed was secondary to noncompliance with her simvastatin regimen. Initially we considered simvastatin as a possible cause (in addition to lisinopril) of this patient's pancreatitis, but despite inadvertent continued exposure to conjugated estrogens and simvastatin, her pancreatitis resolved and did not recur. Hence, it is more likely that lisinopril was the offending agent. Given this patient's history of hypertriglyceridemia and concomitant use of simvastatin and estrogens, we believe it was possible that lisinopril did not solely cause but rather exacerbated pancreatitis in this patient. The point remains, drugs that precipitate pancreatitis in predisposed patients can be avoided only if the causative nature of the medication is recognized.

Because acute pancreatitis is encountered so infrequently in clinical practice, it is not unusual for medications to be overlooked as causative agents when evaluating the patient. For patients prone to pancreatitis, however (such as our patient, who had a strong family history of hypertriglyceridemia), it would be prudent to avoid known pancreatic irritants, including drugs. This report serves as a reminder to those who prescribe drugs that might cause or exacerbate pancreatitis. Even though not all cases of drug-induced pancreatitis are severe or fatal, they can cause serious morbidity in terms of hospitalizations and patient discomfort. Increased awareness will be more likely to result in prevention.

\section{References}

1. Lankisch PG, Droge $M$, Gottesleben F. Drug induced acute pancreatitis: incidence and severity. Gut 1995;37:565-7.

2. Dabaghi S. ACE inhibitors and pancreatitis. Ann Intern Med 1991;115:330-1.

3. Zion MM, Goldberg B. Suzman MM. Corticotrophin and cortisone in the treatment of scleroderma. QJ Med 1955;24:215-27.

4. Johnson DH, Cornish AL. Acute pancreatitis in patients receiving chlorothiazide. JAMA 1959;170: 1054-6.

5. Mallory A, Kern F Jr. Drug-induced pancreatitis: a critical review. Gastroenterology 1980;78:813-20.

6. Mallory A, Kern F Jr. Drug-induced pancreatitis. Baillieres Clin Gastroenterol 1988;2:293-307.

7. Wilmink T, Frick TW. Drug-induced pancreatitis. Drug Saf 1996:14: 406-23.

8. Standridge JB. Fulminant pancreatitis associated with lisinopril therapy. South Med J 1994;87:179-81.

9. Pluhar W. [A case of possible lovastatin-induced pancreatitis in a patient with Gilbert syndrome.] Wien Klin Wochenschr 1989;101:551-4.

10. Nugent CE, Wiersema MJ, Allen HR Jr, Cravens EE, Lehman GA. Benign ulcers of the major papilla with gastrointestinal bleeding. Gastrointest Endosc 1994;40:506-8.

11. Abdul-Ghaffar NU, el Sonbaty MR. Pancreatitis and rhabdomyolysis associated with lovastatin-gemfibrozil therapy. J Clin Gastroenterol 1995:21:340-1.

12. Couderc $M$, Blanc $P$, Rouillon JM, Bauret $P$, Larrey D, Michel $H$. [A new case of simvastatin-induced acute pancreatitis.] Gastroenterol Clin Biol 1991;15:986-7.

13. Berland Y, Vacher-Coponat H, Durand C, Baz M, Laugier R, Musso JL. Rhabdomyolysis with simvastatin use. Nephron 1991;57:365-6

14. Lons T, Chousterman M. [Simvastatin: a new drug responsible for acute pancreatitis?] Gastroenterol Clin Biol 1991;15:93-4.

15. Ramdani M, Schmitt AM, Liautard J, Duhamel O, Legroux P, Gislon J, et al. [Simvastatin-induced acute pancreatitis: two cases). Gastroenterol Clin Biol 1991;15:986.

16. Black DM, Bakker-Arkema RG, Nawrocki JW. An overview of the clinical safety profile of atorvastatin (Lipitor), a new HMG-CoA reductase inhibitor. Arch Intern Med 1998;158:577-84.

17. Fortson MR, Freedman SN, Webster PD 3rd. Clinical assessment of hyperlipidemic pancreatitis. Am J Gastroenterol 1995;90:2134-9. 